\title{
EL BORRADO EN LA PINTURA CONCEPTUAL. DE LA ICONOGRAFÍA DE DÁNAE A LA DE SÉMELE EN HILARIO BRAVO
}

\author{
Angélica García-Manso \\ Universidad de Extremadura \\ angelicamanso@hotmail.es
}

\section{RESUMEN}

Dentro de los planteamientos conceptuales que definen la estética del pintor Hilario Bravo, la transformación de una obra constituye una respuesta normalizada en el arte del siglo xx. Ahora bien, en pocas ocasiones la radicalidad de la transmutación provoca que la obra cambie de título y de sentido de forma absoluta. Sucede con Flammae, obra del año 2014 dentro de una serie dedicada a la relación entre la llama, el pensamiento y el acto de creación, que en 2017 se transforma en Sémele, en unos momentos donde lo que prima en el artista es la búsqueda del catasterismo como proyección última del fuego. Ello posee implicaciones hermenéuticas clave, tanto desde una perspectiva mitológica como desde la iconografía de la tradición cristiana, pero, sobre todo, da cumplimiento al sentido de la obra: una pintura sobre el proceso creativo que deriva en reflexión sobre la inmanencia de la propia obra.

Palabras clave: Hilario Bravo, borrado, pintura conceptual, mitología clásica, iconografía cristiana.

ERASURE IN CONCEPTUAL PAINTING.

FROM THE ICONOGRAPHY OF DANAE TO THAT OF SEMELE IN HILARIO BRAVO

\section{Abstract}

Within the conceptual approaches that define the aesthetics of the painter Hilario Bravo, the transformation of a work is a standard response in 20th-century art. On a few occasions, however, the radical nature of the transmutation causes the work to change its title and meaning completely. This is the case with Flammae, a work from 2014 in a series dedicated to the relationship between flame, thought and the act of creation, which in 2017 is transformed into Semele, at a time when the artist's main concern is the search for cathasterism as the ultimate projection of fire. This has key hermeneutical implications, both from a mythological perspective and from the iconography of the Christian tradition, but, above all, it fulfils the meaning of the work: a painting about the creative process that leads to a reflection on the immanence of the work.

Keywords: Hilario Bravo, Erasure, Conceptual Painting, Classical Mythology, Christian Iconography. 


\section{INTRODUCCIÓN: BREVE CONTEXTUALIZACIÓN DEL BORRADO EN LA PINTURA CONTEMPORÁNEA}

En la historia del arte, los motivos de reelaboración, reciclaje, reutilización, enmienda, tachado, destrucción, etcétera, aparecen asociados de forma natural a la propia realización artística y se pueden aducir ejemplos de borrado desde sus mismos orígenes, desde el arte prehistórico. No ha sido hasta el pasado siglo xx cuando se ha llevado a cabo una reflexión profunda sobre tales procesos, que ha permitido un desglose contextual y conceptual de estos (Mora 2016). En efecto, en lo que se refiere a una perspectiva contextual y por señalar únicamente dos ejemplos, a la motivación estética (o de imposibilidad de hacer corresponder la idea y su ejecución) se añaden otras de índole política, que abarcan desde la censura, la autocensura e incluso, cuando se interviene al margen del creador, de la apropiación de autoría y de la damnatio memoriae. Desde una perspectiva específicamente conceptual, y de nuevo por recoger únicamente dos situaciones, es posible descubrir la voluntad expresa del artista al respecto, sea por proponer como parte de su reflexión estética la destrucción de la obra, sea por propugnar un diálogo de una obra en continua reelaboración y transformación hasta su fijación como palimpsesto (Genette 1989). $\mathrm{Y}$ es que, aunque el concepto de emendatio como borrado proceda de la crítica textual, su aplicación a la obra artística implica una relectura e interpretación no del resultado final, sino del propio proceso de cambio; de ahí que se puedan emplear como sinónimos.

Así, en numerosas ocasiones, las técnicas espectométricas con rayos X, ultravioletas e infrarrojos contemporáneas revelan, a través de fotografías fluorescentes (Juanes y Roldán 2008), ese diálogo entre creador y creación en la pintura consagrada en la historia del arte; no obstante, y de forma llamativa, en la pintura más contemporánea se integra y se expresa en la obra el proceso de creación sin necesidad de una cirugía no invasiva posterior. Los ejemplos son numerosos: pintores como Miró, Tàpies o Vostell -por señalar tres casos íntimamente relacionados con España y, de alguna manera, también con la obra de Hilario Bravo- reflejan una relación casi física con el proceso de reelaboración y transformación de creaciones que se ven de esta manera enriquecidas tanto formal como hermenéuticamente y dan lugar al concepto general de «obra abierta» establecido por Umberto Eco (Eco 1984). No es casual que los tres artistas mencionados establecieran -desde perspectivas estéticas distintas, ciertamente- una reflexión profunda sobre el collage como manifestación modélica del palimpsesto pictórico y del diálogo entre autor y obra, desde el Miró que abdicó de la pintura o desde el informalismo orgánico de Tàpies, y que, en el caso de Wolf Vostell, llega a expresarse de manera inversa como «décollage».

Stricto sensu, ninguno de los creadores citados como ejemplo se inscribe en el movimiento conceptual (Morgan 2003). Ello resulta importante por cuanto, en líneas generales, sus obras establecen una lectura acumulativa, de acuerdo con la cual los cambios y variaciones añaden claves interpretativas a la creación sin que varíe sustancialmente su sentido (Panofski 1986). No sucede lo mismo en el caso de obras conceptuales, donde, casi por definición, la transformación impone un cambio de significado. 


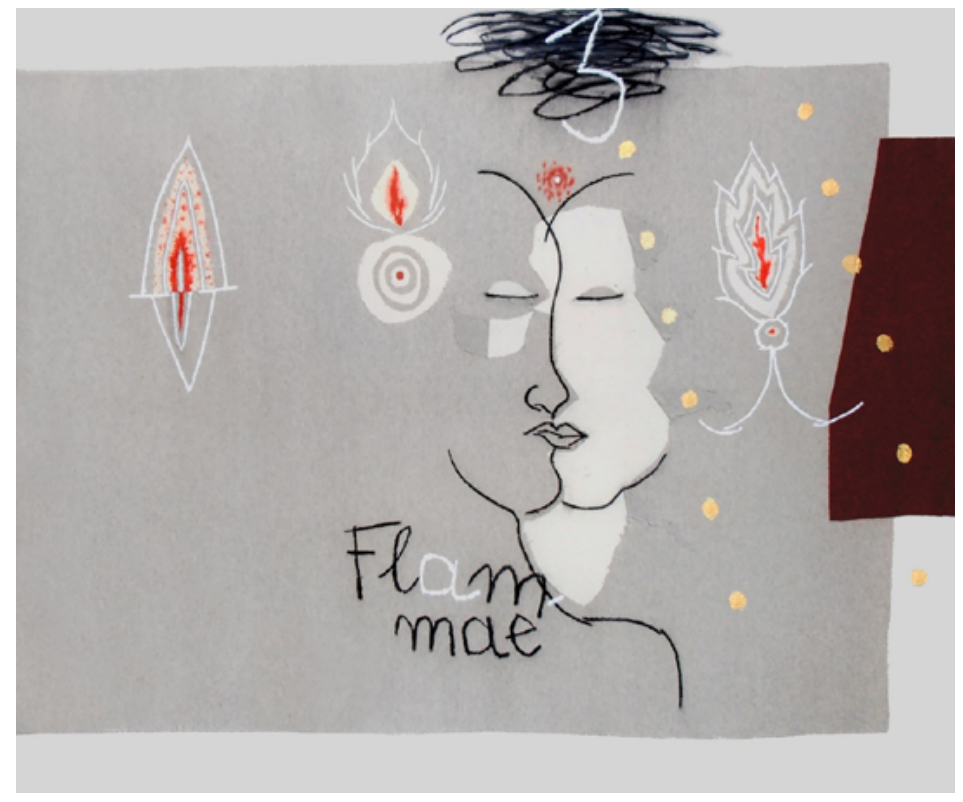

Fig. 1. Hilario Bravo, Flammae, 2014, 162×195. Obra destruida por el artista.

Reproducción con permiso del pintor.

La trayectoria creativa de Hilario Bravo (Cáceres, 1955) se inscribe en líneas generales en la estética conceptual (Lozano Bartolozzi 2008a, 2008b; García Manso y Tovar 2020), mediante la que impone un esfuerzo de comprensión, cuyas claves de lectura el propio artista suele facilitar al organizar sus creaciones en series. No es este el lugar indicado para desglosar las diferentes facetas del trabajo artístico de Hilario Bravo, que se encuentran reunidas en su blog hilariobravo.blogspot.com, ni la repercusión académica que su obra ha generado (Bravo 2014), así como las colecciones públicas y privadas en las que se incluyen sus creaciones. Aun así, se hace preciso señalar cómo, una vez superada su etapa de iniciación en el entorno artístico del País Vasco entre los ańos setenta y ochenta del pasado siglo, su producción pictórica posee prácticamente desde sus orígenes una doble impronta: de un lado, su inspiración en textos de índole antropológica, en mitos y leyendas; de otro, su correlación con la sensualidad femenina. Derivadas de esa doble impronta, sus series articulan una gramática con elementos procedentes de grafías de escritura como pictogramas (pinturas rupestres, runas, formas de diferentes alfabetos, etcétera) y elementos temáticos relacionados con la naturaleza, como, entre otros, los ríos, el fuego o el firmamento. Dicha gramática se sitúa en lugares como Roma, México y, de forma destacada, Extremadura, como jalones de su propia peripecia vital. El pintor también articula esa gramática en torno a referentes literarios universales, entre los que se cuentan Catulo, Virgilio o Dante, por citar únicamente tres. 


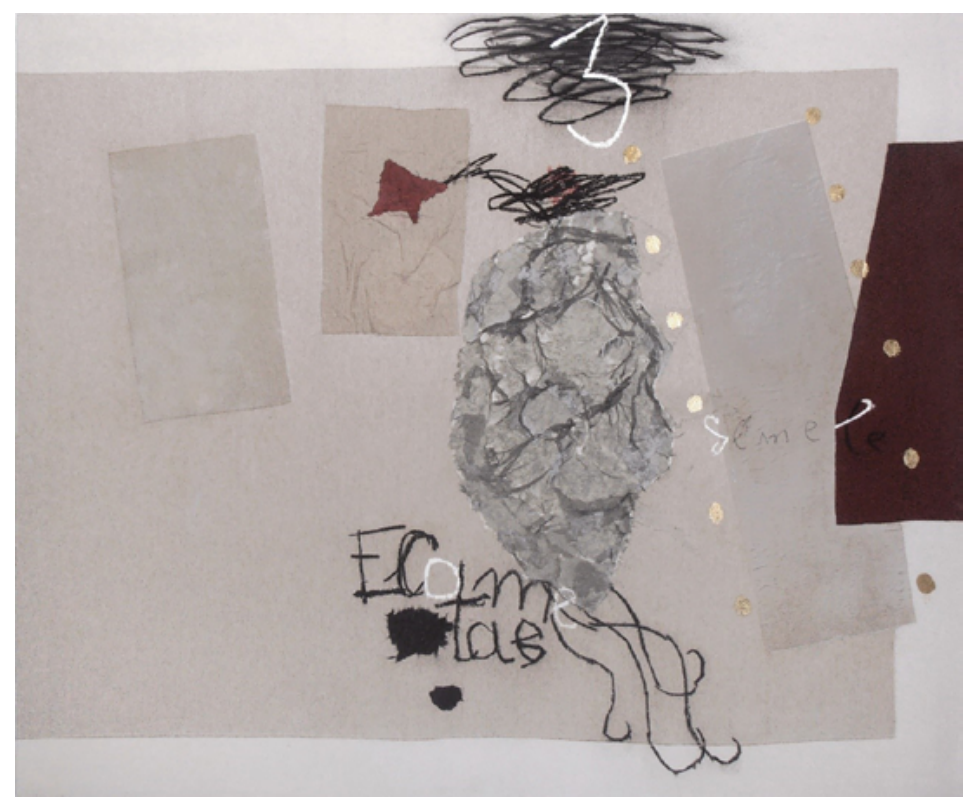

Fig. 2. Hilario Bravo, Sémele, 2017, 162×195. Colección particular del artista. Reproducción con permiso del pintor.

De acuerdo con ello, entre las series pictóricas más recientes del pintor se cuenta Las paredes de la idea / Cabezas (2014), en la que, en líneas generales, se plasma la reminiscencia de la cueva platónica que evoca la cavidad craneal y en la que el fuego ilumina el interior del cerebro (Fernández Campón 2014). Se trata de una serie de la que, a partir de la noción de fuego, surge la serie Constelaciones (2016), donde Bravo experimenta con la idea de firmamento como una llama exterior que define lo humano. Como gozne entre ambas series, entre Las paredes de la idea y Constelaciones, Bravo ha propuesto una obra que pertenece a las dos de forma simultánea. Se trata de Flammae (2014; acrílico, oleo, carboncillo, pan de oro y collage sobre tela) y, a la vez, de Sémele (2017; acrílico, oleo, carboncillo, pan de oro y collage sobre tela), pues, en realidad, el cuadro es el mismo (en colección particular). Es decir, Flammae ha evolucionado hacia Sémele a partir de un proceso de alteración que, antes de proceder a detallarlo en el próximo epígrafe, básicamente ha consistido en velar los motivos figurativos más evidentes para, una vez anulados, generar una nueva interpretación de la pintura, si bien a partir de una especie de combustión interna, del propio fuego generado por la lectura conceptual de la pintura.

Recientemente, García-Manso (García-Manso 2021) ha estudiado la sintaxis iconográfica de Flammae, a partir de la fusión de dos referentes: uno pagano, inspirado en la figura mitológica de Dánae y en la tradición pictórica asociada al relato, fundamentalmente en Tiziano, Rubens y Tintoretto (Maffre 1986), y otro cristiano, donde la celebración de Pentecostés se hace presente en el lienzo a partir 
de una iconografía cuyo referente de más relieve es la conocida pintura de El Greco (Pentecostés, 1600, Museo del Prado, Madrid). Tanto a propósito de Dánae como en relación con Pentecostés, la lluvia, sea de fuego o de oro, constituye el elemento primordial por intervención de una divinidad, sea pagana, como Júpiter/Zeus, sea el dios cristiano.

Por lo demás, la referencia mitológica alude a momentos de engendramiento, se trate de Perseo, hijo de Dánae, o de Dionisos/Baco en lo que concierne a Sémele, lo cual facilita la transición de la obra, más si cabe cuando se utiliza el fuego como intermediario, elemento omnipresente en el conjunto de la serie Las paredes de la idea / Cabezas, y, por descontado, en la celebración cristiana de Pentecostés y en la propia figura mitológica de Sémele, que da título a la pintura en su fase última.

\section{ANÁLISIS DE LA TRANSFORMACIÓN FIGURATIVA Y CONCEPTUAL DE FLAMMAE A SEMELE}

La mutación de Flammae en Sémele implica unos cambios figurativos que afectan fundamentalmente a tres aspectos: las figuras de las lucernas-vulva, las figuras de los rostros y, en tercer lugar, los elementos alfabéticos. Así, en lo que se refiere a la primera alteración, en la nueva pintura las tres lucernas-vulvas aparecen tapadas con retales, en una especie de patchwork de cortes rectangulares rectos, de manera que, en realidad, desaparecen como formas que han sido censuradas. También los rostros del centro de la imagen han desaparecido, emborronados como con una cubierta de un capullo u ovillo informe. La estrella que fundía sus frentes se ha transformado en el dibujo naïfy a la manera de un tachón para formar una especie de cometa. En la parte inferior, el trazo se ha multiplicado en una especie de ondas que parecen recrear flujos líquidos, conforme un motivo y una forma de trazo habituales en la poética de Hilario Bravo, sobre todo la relacionada con las aguas, como sucede en la serie de grabados Dríada. La ninfa sedienta (2007) (García-Manso 2008).

En fin, la parte alfabética también ha sido objeto de una fuerte transmutación, que va desde la palabra "flammae» a la expresión "Est cometa», a la que se añade, supraescrita sobre la cubierta de la tercera vulva la palabra, el sustantivo "Sémele»; de tal forma que se ha avanzado textualmente desde la llama de fuego hacia la declaración de que «aparece un cometa» al que se dota de nombre propio. El conjunto refleja un fuerte proceso de eliminación, del que se salva el camino formado por los puntos de pan de oro que caen diagonalmente ocupando la parte derecha de la obra. Apenas quedan restos figurativos, excepción hecha de las líneas que evocan un cometa y los manantíos inferiores.

No obstante, los elementos mantienen la impronta estética del pintor, a pesar de los parches y las manchas. Así, según hemos indicado, los flujos de la parte inferior remiten a la creación de las ninfas de los ríos, en tanto en la parte superior la estrella plantea una línea de trabajo que ocupará al pintor en la incipiente serie Constelaciones, a la que ya pertenece Sémele.

Según quedó establecido en el estudio de García-Manso (2021), Flammae superpone conceptualmente dos relatos, uno mitológico de procedencia clásica o, 


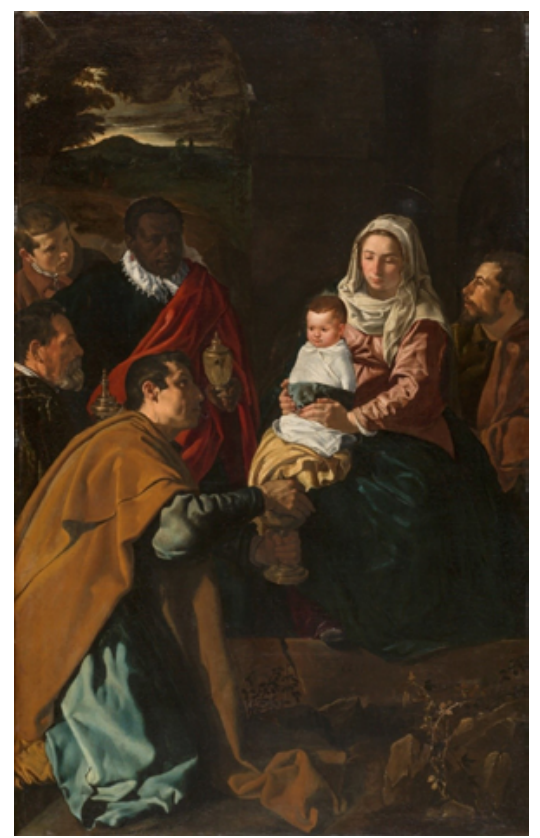

Fig. 3. Diego Velázquez, La adoración de los Reyes Magos, 1619, 204x126,5, Museo del Prado, Madrid. Imagen de uso libre.

por así decir, de inspiración pagana; y otro de clave religiosa cristiana, los cuales aparecen sintetizados o fundidos. Lo mismo sucede con Sémele, que mantiene la presencia del doble relato, mitológico y religioso. Así, la narración mitológica acerca de Dafne fecundada por la lluvia dorada que late en la pintura de Bravo en los puntos brillantes que caen conforme a una iconografía suficientemente contrastada en la historia del arte se transforma en el de una Sémele, también fecundada, que fue carbonizada por el rayo del mismo Zeus, a quien esta quiso ver en todo su poder, lo cual la abrasó.

En lo que a la clave cristiana se refiere, las lenguas de fuego de Pentecostés de Flammae se transmutan en una sui generis Natividad en Sémele, en la que los rectángulos evocan las figuras tradicionales en un Nacimiento, como pueden ser los tres magos de Oriente, guiados por el cometa, que descubren el ovillo de pañales que cubre al niño; entre las dádivas de los magos, el oro en las monedas, el incienso y la mirra en las manchas oscuras y en el líquido que mana (Réau 2002). Una pintura que puede ser objeto de contraste a este respecto es La adoración de los Reyes Magos, de Velázquez (1619; Museo del Prado, Madrid), sobre todo en lo que se refiere a la figura del niño, ya no recién nacido y colocado en marcada verticalidad, con una disposición de volúmenes concomitante con la que ofrece Hilario Bravo. Además, el fondo atmosférico, con un resplandor de atardecer en un fuerte contraste oscuro, con nubosidad, está presente en la parte superior de la pintura conceptual. De hecho, 

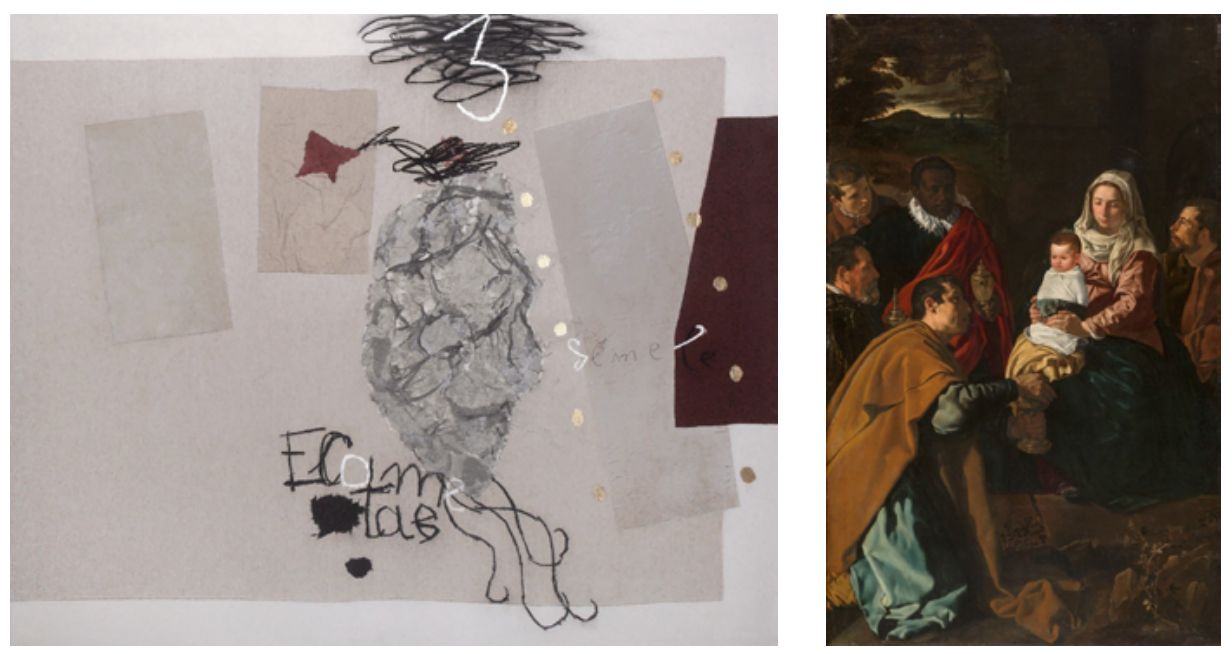

Fig. 3 bis. Comparación sinóptica entre Sémele, de H. Bravo, y La adoración de los Reyes Magos, de D. Velázquez.

por señalar algunos ecos: la mínima ondulación resplandeciente que abre las nubes al fondo aparece en Velázquez y su giro está presente en la línea del cometa en Bravo. De igual forma se puede descubrir una alusión en la tela azul del rey mago arrodillado en el primer plano de la obra velazqueña y los manantíos en Sémele.

En fin, Sémele también estaba embarazada en el momento en que se manifiesta Júpiter ante ella; al cabo, nacerá una divinidad tan señalada como Dionisos a través del injerto que el padre de los dioses olímpicos hace del feto en su pierna una vez que ella resultó calcinada. En otras palabras, el relato también responde al de una natividad, aunque esta sea sui generis. De hecho, el revoltijo del centro de la pintura no deja de evocar una pierna hinchada como un vientre a punto de dar a luz. Al tiempo, se produce un catasterismo o ascenso a las estrellas de Sémele a manos de su hijo Dionisos, según relata una de las fuentes textuales más importantes del mito, la de la Biblioteca Mitológica de Apolodoro (3.38) (Apolodoro [PseudoApolodoro] 1987).

De cualquier forma, la iconografía asociada a Sémele no aparece del todo definida en la tradición pictórica (Kossatz-Deissmann 1994), pues entra en colisión con la idea de deslumbramiento presente, por ejemplo, en el relato mítico de Psique (mito que, a pesar de proceder de una elaboración literaria, en la historia del arte ha generado una atención propia con un calibre semejante al de otros mitos grecolatinos). De hecho, el icono central remite tanto al rayo de Zeus como a la figura de Dionisos; incluso en Jupiter et Semélé, de Gustave Moreau (1895, Musée National Gustave Moreau, Paris), el relato mitológico se presenta como una especie de retablo cristiano. No obstante, el elemento central viene dado por el momento de la revelación, del desvelamiento, y para ello se procede iconográficamente a partir de 


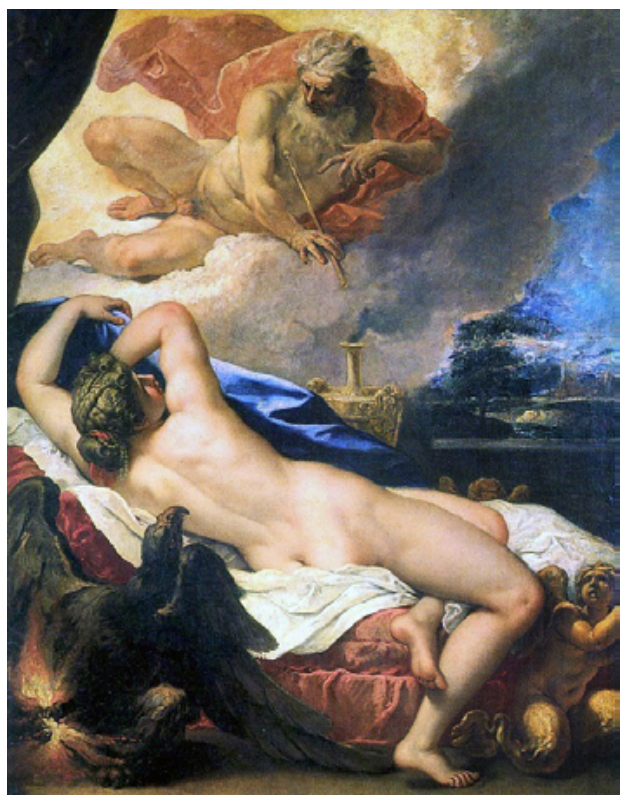

Fig. 4. Sebastiano Ricci, Giove e Semele, 1695, 191x151, Galleri degli Uffizi, Firenze. Imagen de uso libre.

la nube oscura, desde la que surge y de la que resalta el resplandor mortal del padre de los dioses. Es el juego de contraste entre oscuridad y luz el que se presenta en pinturas como las que dedican a Sémele pintores clásicos como Rubens (Jupiter et Semélé, 1636, Musées Royaux des Beaux-Arts, Bruxelles) o Sebastiano Ricci (Giove e Semele, 1695, Galleri degli Uffizi, Firenze), entre otros. De esta manera, Hilario Bravo, al mantener la figura geométrica de la derecha, conserva como nube lo que en el mito de Dánae era el cortinaje del dosel del lecho que enmarcaba la caída de la lluvia dorada, en tanto el nivel superior mantiene la aparición de la divinidad que resplandece entre nubarrones y claroscuros.

\section{CONCLUSIÓN: \\ LA TRANSFORMACIÓN CONCEPTUAL QUE IMPLICA SÉMELE}

¿Por qué evoluciona Flammae en concreto y no otras pinturas de la misma serie de Las paredes de la idea / Cabezas? No es habitual en la trayectoria de Hilario Bravo que, una vez expuesta una obra, esta sirva como respaldo de una nueva creación de cariz diferente. Cosa distinta es que los cambios se produzcan dentro de la propia pintura, como sucede, por poner un par de ejemplos, con las soluciones alfabéticas, presentes también en la evolución de Flammae, según hemos visto. Sucede en uno de los grabados de la serie Dríada. La ninfa sedienta (2007) antes 
citada. En dicho grabado, la palabra «Tajo», con la letra «a», aparece reescrita para transformarse en «e», conforme el nombre del río en lengua portuguesa, dado que este cambia de país (García-Manso 2008); sucede en la misma serie de Las paredes de la idea / Cabezas, en la pintura Fontis patet (2014), con un juego morfosintáctico sobre la expresión en lengua latina, escrita como "Fons patet» o como "Fontis patet» (García-Manso y Tovar 2020).

Pero, tal como se ha analizado en los epígrafes previos, la mutación de Flammae a Sémele deviene radical, pues no solo implica la destrucción de una obra previa, sino su reinterpretación y renacimiento consiguiente. De esta forma, puede existir un motivo conceptual de fondo. $Y$ es que en la transformación se descubre una expresión lógica interna: Sémele es destruida por el fuego al igual que lo es simbólicamente la pintura matriz, cuyo título es elocuente al respecto, Flammae. De esta forma, parece darse una especie de cumplimiento socrático, de acuerdo con el que el sentido de una acción se descubre en su realización plena: una obra sobre el fuego adquiere trascendencia si es simbólicamente destruida por este una vez consumado su sentido. A este respecto, Hilario Bravo elige una de las pinturas más ricas o sugerentes de la serie Las paredes de la idea / Cabezas, para la que propugna no solo el velado, sino una especie de retorno a un estado de larva, de capullo, que ocupa el centro de la obra. En otras palabras, con la transformación se establece una especie de retorno al pasado, una inversión temporal que incluso puede ser de cariz cosmogónico (pues la nueva serie se refiere a las Constelaciones y, por ende, al universo), a un estado embrionario previo a la primera pintura. Ello da lugar a una última paradoja conceptual: el pintor propone no solamente un proceso de autocensura, sino, sobre todo, un viaje a formas y geometrías básicas que hace coincidir con su etapa de madurez creativa. En fin, de alguna manera el pintor queda preńado de Dionisos antes del deslumbramiento que le ha provocado Flammae y lleva a cabo un particular ajuste de cuentas consigo mismo al borrar la obra. 


\section{BIBLIOGRAFÍA}

Apolodoro [Pseudo-Apolodoro]. (1987). Biblioteca mitológica (edición y traducción de José Calderón Felices). Madrid: Akal.

Bravo, H. (2014). Las paredes de la idea. Notas en la niebla. Blog [Internet]. Disponible en http:// hilariobravo.blogspot.com/2014/02/; consulta hecha el día 15/03/2021.

Eco, U. (1984). Obra abierta. Barcelona: Planeta-Agostini.

Fernández Campón, M.A. (2014). Hilario Bravo. Cabezas. Las paredes de la idea. Catálogo. Pamplona/Cáceres: Ayuntamiento de Pamplona / Diputación Provincial de Cáceres.

García-Manso, A. (2008). «Dríada 2007: Reflexiones en torno a la Ninfa Sedienta de Hilario Bravo". Ars et Sapientia. 25:61-69.

García-Manso, A. (2021). «El Pentecostés pagano de Hilario Bravo». Eviterna [Internet]. 9:3448. Disponible en https://doi.org/10.24310/Eviternare.vi9.11129; consulta hecha el día $12 / 04 / 2021$.

García-Manso, A., Tovar Paz, F.J. (2020). «Filología y pintura conceptual: Análisis de dos obras de Hilario Bravo». Cartaphilus: Revista de Investigación y Critica Estética [Internet]. 18:134-147. Disponible en https://doi.org/10.6018/cartaphilus.441801; consulta hecha el día 24/03/2021.

Genette, G. (1989). Palimpsestos. La literatura en segundo grado. Madrid: Taurus.

Juanes, D., Roldán, C. (2008). «Fluorescencia de Rayos-X mediante equipo portátil aplicada al estudio y conservación del patrimonio cultural», en Calderón, T., Del Egido, M., editores, La Ciencia y el Arte. Ciencias experimentales y conservación del Patrimonio Histórico. Madrid: Ministerio de Cultura, pp. 140-151.

Kossatz-Deissmann, A. (1994). Sub voce Semele, en Linant de Bellefonds, P., Müller, P., editores. Lexicon Iconographicum Mythologiae Classicae, vol. 7. Basel/München: Artemis. pp. 718-726.

Lozano Bartolozzi, M.M. (ed.) (2008a). Plástica extremeña. Badajoz: Fundación Caja Badajoz.

Lozano Bartolozzi, M.M. et al. (2008b). El pulso del arte contemporáneo. Artistas de la colección de la Asamblea de Extremadura. Mérida: Asamblea de Extremadura.

Maffre, J.J. (1986). Sub voce Danae. En: Augé, C., Müller, P., editores. Lexicon Iconographicum Mythologiae Classicae, vol. 3. Basel/München: Artemis. pp. 325-357.

Mora Suárez-Varela, V.L. (2016). «Del arte nihilista a la literatura tachada: Tachones, borraduras y reescrituras colectivas», en Durante Asensio, I., García Alarcón, A., Hernández Navarro, M.A. editores, Contratiempos. Gramáticas de la contemporaneidad en el arte reciente. Murcia: Cendeac. pp. 101-120.

Morgan, R.C. (2003). Del arte a la idea: Ensayos sobre Arte Conceptual. Madrid: Akal.

PAnofski, E. (1986). El significado de las artes visuales. Madrid: Alianza.

RÉAU, L. 2002. Iconografía del arte cristiano, vol. 2. Barcelona: Serbal. 